\title{
Correction to: Performance of numerical weather prediction models in predicting track of recurving cyclone Vayu over Arabian Sea during June 2019
}

Krishna Mishra, M Sharma and M Mohapatra

Correction to: J. Earth Syst. Sci. (2021) 130:25 https://doi.org/10.1007/s12040-020-01533-7

Due to an oversight, figure 3 (Article ID 25) of the article was published with an incorrect figure. The correct figure 3 is given below.

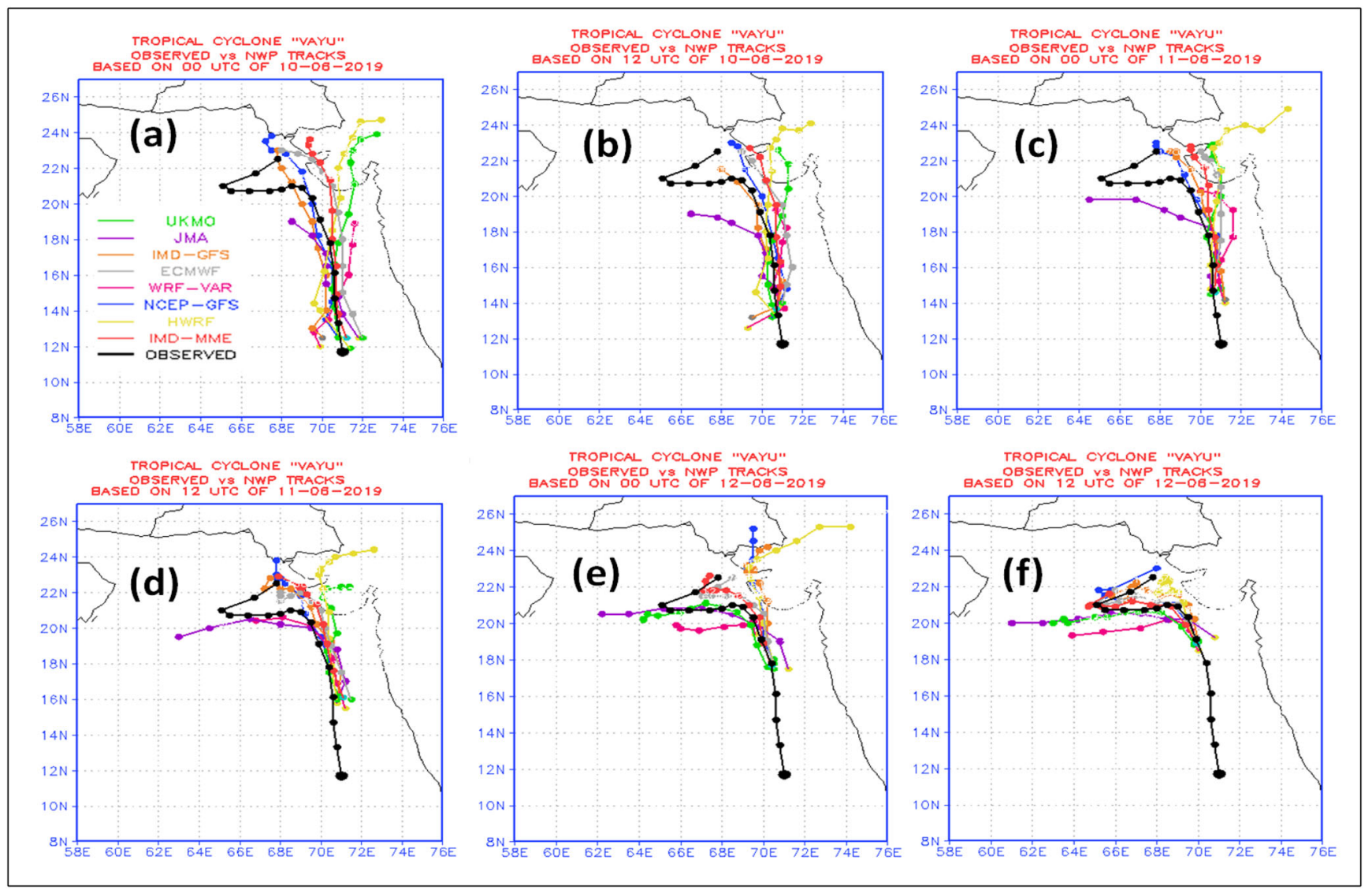




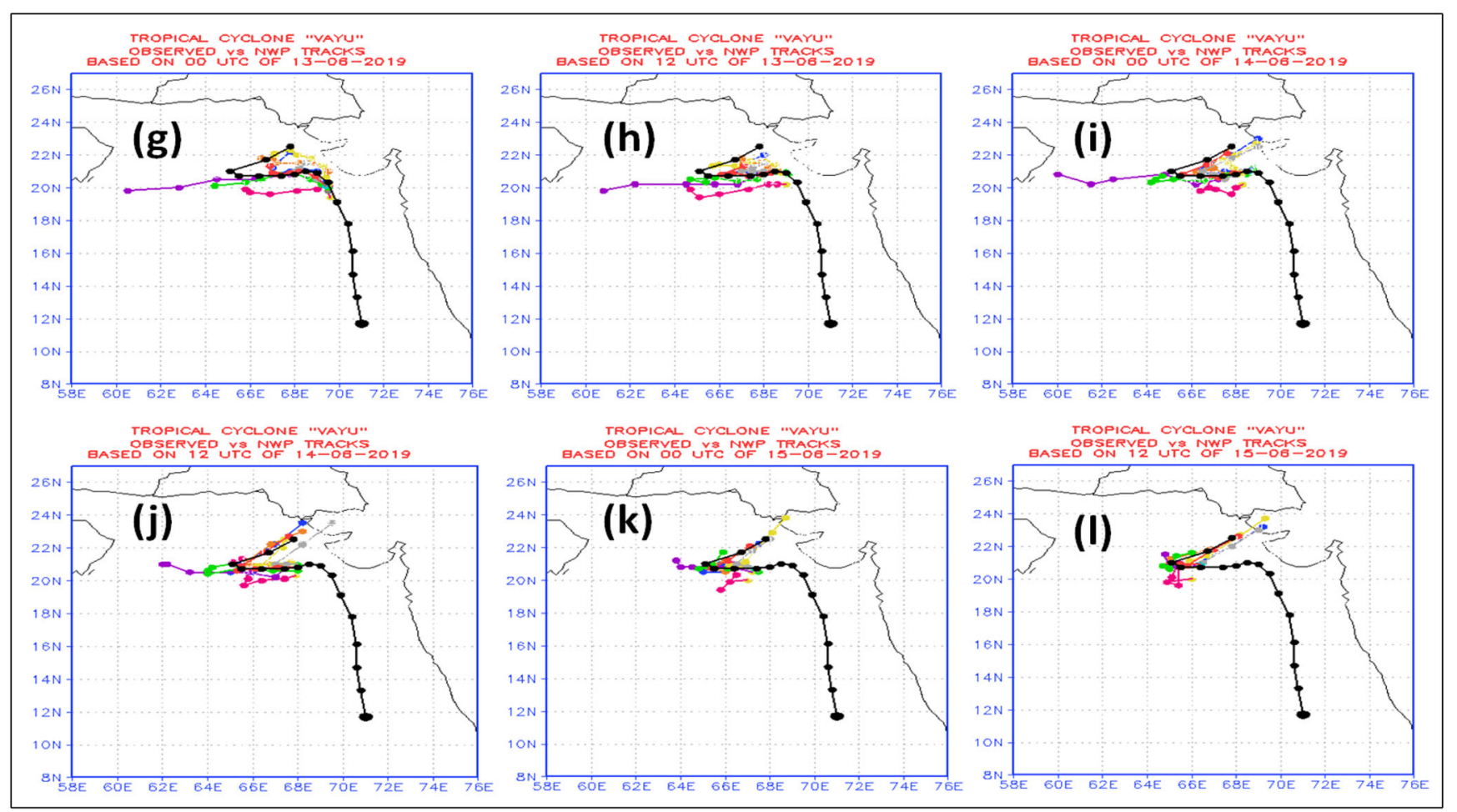

Figure 3. (a-l) Forecast tracks by different models based on 00 and 12 UTC during 10-15th June along with observed tracks. 